\title{
Productivity of Unorganised Manufacturing Enterprises in India
}

\author{
Akash Dandapat, Soumita Dasgupta and Pinaki Das* \\ Department of Economics, Vidyasagar University, Midnapore, West Bengal, India \\ *Corresponding author: pdasvu@mail.vidyasagar.ac.in (ORCID ID: 0000-0002-3861-1056)
}

Received: $14-01-2021$

Revised: 03-02-2021

Accepted: 10-03-2021

\begin{abstract}
Since unorganised manufacturing enterprises (UMEs) provide employment to a huge mass in India therefore its growth and productivity is a matter of concern. Thus, through this paper the growth and productivity of Indian UMEs are shown with the help of NSSO Data (67 th and $73^{\text {rd }}$ Rounds). This paper reveals that the number of UMEs increased significantly in India during 2010-11 to 2015-16. The average productivity of labour increased over time. Using the Cobb-Douglas production function it was further found that the marginal productivity of labour is much higher than the marginal productivity of capital. Productivity is found to be positively and significantly influenced by male ownership, own account enterprises, enterprises do not face problem, expanding status of growth, government assistance, registration of enterprises and capital intensity.

\section{Highlights}

(0 The number of UMEs, employment and GVA increased during 2010-11 to 2015-16. Productivity is influenced by different characteristics of UMEs and their status of growth.
\end{abstract}

Keywords: Manufacturing Enterprise, Unorganised, Growth, Productivity, Employment

Unorganised Manufacturing Enterprises (UMEs) have been playing a very important role in Indian economy. If we assume that the labour force participation rate would remain at about 60 per cent in the next two decades, then about 55-60 lakh jobs will have to be created annually. With a demographic dividend (majority of the working age population) and only 6.6 per cent growth rate of the Indian agriculture sector (Economic Survey, 2018-19); India cannot push up her overall growth rate with organised industries. Again, Government data reveals that in India 99 per cent enterprises were unorganised in which 73.3 per cent workers were employed (NSSO 2010-11 \& ASI 2010-11). Therefore, it's the time to look upon the unorganised sector that feeds the majority. This unorganised sector includes those enterprises with which we are much more familiar; some of them are agriculture and allied activities; manufacturing of foods, beverages, beedi, textiles, wearing apparels, papers, metals and electronic equipment; construction; drivers, loaders and unloaders, fruit vendors and other vendors and so on. The quick engagement of the common workers in these sectors made it much more attractive irrespective of gender and caste throughout the country. Nowadays, we have advanced and easily affordable small machines that can be used for such types of unorganised activities to increase productivity and make business much more remunerative. Moreover, these activities have always empowered women by engaging them right from their home. Accessible banking service at every gram panchayats with appropriate Government

How to cite this article: Dandapat, A., Dasgupta, S. and Das, P. (2021). Productivity of Unorganised Manufacturing Enterprises in India. Economic Affairs, 66(1): 09-16.

Source of Support: None; Conflict of Interest: None (c) 
support through various schemes have attracted the youths to engage in such activities considerably.

Kanitkar (1994) advocated that UMEs growth stimulates competition and entrepreneurship which, in turn, enhances efficiency, innovation, and productivity growth. Raj and Sen (2015) showed that the financial constraint is a major barrier of transition of a firm from OAMEs to NDMEs, and NDMEs to DMEs. Manikandan, Kanagasabapathi and Sreeleakha (2015) concluded that the informal sector is growing faster than formal. Dutta (2019) studied the Development of rural enterprises in West Bengal and Gujarat. Basole, Basu \& Bhattacharya (2015) analysed the sub-contract and non-contract perspectives of UMEs. Sen and Salim (2016) studied the MSMEs in the Districts of West Bengal. Goldar and Mitra (2013) measured the efficiency of the informal enterprises based on the 2005-06 NSSO data. Rao and Dasgupta (2009) analysed the employment, output and structure of the food processing sector for both the organised and unorganised manufacturing sector. Unorganised manufacturing enterprises (UMEs) reduce poverty and vulnerability of the poor through enabling them to enhance selfempowerment and social dignity (Chowdhury 2009). They are important sources of employment creation, income generation, product diversification and economic growth (Hussain 2000). Agyapong (2010) pointed out that UMEs have been identified to play a key role in a society by contributing to jobs through innovations and creativity as well as aiding human resource development. Mariappan (2011) estimated the productivity and showed the returns to scale for two digit level industries in Indian unorganised manufacturing sector. Ganguly (2013) showed the UMEs in West Bengal faced very tough situation due to utmost competition in national and international level from large industries due to lack of infrastructure, lower volume of capital, lack of product standardization, lack of access to modern technology etc. Subramanian (2010) finds that UMEs are important in creating employment and entrepreneurial talent among the Malaysian youth where MMEs provide young and budding entrepreneurs an opportunity to be involved in entrepreneurships that require less financial commitment. Unni, Lalitha and Rani (2001) analysed trends of the economic reforms and productivity in Indian manufacturing sector.
We have numerous research works dealing with the organised sector but if we talk about the Indian unorganised sector and its various dimensions there is still a lot of work to be done to explore this sector. Moreover, there are numerous questions regarding this sector which are still unexplored. To point out a few are: What is the nature of growth of UMEs in India? What are the average and marginal productivities of UMEs in India and her states? What is the nature of return to scale of UMEs? What are the factors that may explain the productivity of UMEs? Thus through this paper an attempt has been made to resolve the above stated questions which explore the present growth and productivity status of the Indian unorganised manufacturing sector across states. For fulfilling these objectives we have taken the data from National Sample Survey Organization (NSSO) on Unincorporated NonAgricultural Enterprises (Excluding Construction) in India of the $67^{\text {th }}(2010-11)$ and $73^{\text {rd }}(2015-16)$ Rounds.

\section{MATERIALS AND METHODS}

This paper tries to examine and estimate the average productivity of labour and capital, marginal productivity of labour and capital, capital intensity, returns to scale and utilization capacity. The labour productivity can be measured by the ratio of gross value added to labour (i.e., Q/L) which shows the amount of gross value added generated per employee whereas the capital productivity can be measured by the gross value per unit of fixed capital (i.e., $\mathrm{Q} / \mathrm{K}$ ) which shows the amount of gross value added generated per unit of capital. Capital intensity is measured by gross fixed capital to per employee (i.e., K/L) which shows the number of fixed capital allotted per employee.

Returns to scale measure the response of output to proportionate change in inputs. It is an important indicator of production technique. Returns to scale are of three types, increasing returns to scale (IRS), decreasing returns to scale (DRS) and constant returns to scale (CRS). The production technique shows the IRS, if the rate of increase in output is higher than the rate of increase in input. In case of DRS, the rate of increase in output is lesser than the rate of increase in input. Whereas, in case of CRS, the rate of increase in output is equal to the rate of increase in input. 
To know whether the production technique is showing IRS or DRS or CRS we can use the Cobb Douglas Production Function (CDPF). The CDPF in its stochastic form may be written as:

$$
Q_{i}=A L_{i}^{\alpha} K_{i}^{\beta} e^{u_{i}}
$$

Where, $i=$ No. of enterprises; $Q=$ Gross value added; $A=$ Efficiency parameter; $L=$ Labour input; $K=$ Capital input; $u=$ Stochastic disturbance terms; $e=$ Base of natural logarithms.

The above mentioned CDPF is in non-linear form. However, we can transform it into a linear form by taking log in both the sides; as written below

$$
\operatorname{Ln} Q_{i}=\ln A+\alpha \ln L_{i}+\beta \ln K_{i}+u_{i}
$$

We can rewrite the above equation as mentioned below:

$$
\operatorname{Ln} Q_{i}=A_{0}+\alpha \ln L_{i}+\beta \ln K_{i}+u_{i}
$$

where $A_{0}=\ln A$.

The above model is in linear form and therefore it is a linear regression model. So we can use Ordinary Least Square (OLS) technique to estimate the parameters.

\section{Properties of CDPF:}

1. The partial elasticity of output with respect to labour is measured by $\alpha$. It indicates the percentage change in output for, say, a 1 percent change in labour input, keeping the capital input constant.

2. Also $\beta$ measures the partial elasticities of capital input, keeping the labour input constant.

3. The sum of $\alpha+\beta$ shows the returns to scale. If $\alpha+\beta=1$ then the production function is CRS. If $\alpha+\beta>1$, it is IRS and if $(\alpha+\beta)<1$, it is DRS.

Using the OLS method we have estimated the above function to find out the estimated value of $\alpha, \beta$ and marginal productivities. This regression equation is estimated for the years 2010-11 and 2015-16.

It is hypothesised that the labour productivity (average) of an enterprise depends on the location of enterprise (LOCN), social ownership (OWRSP), type of enterprise (ENT), life-span of enterprise (LIFS), enterprise facing problems (PROB), growth status (STGR), registration under any act (REG), government assistance (GOVAT) and enterprise having agreement with other units (LINK).

The relationship between the labour productivity (PRODUCTIVITY) and the above mentioned explanatory variables can be analysed by the following regression equation:

$$
\begin{aligned}
& \text { PRODUCTIVITY }_{i}=\beta_{0}+\beta_{1} \text { LOCN }_{i}+\beta_{2} \text { OWRSP }_{i}+\beta_{3} \\
& \text { ENT }_{i}+\beta_{4} \text { PROB }_{i}+\beta_{5} \text { GOVAT }_{i}+\beta_{6} \text { STGR }_{i}+\beta_{7} \text { REG }_{i} \\
& \quad+\beta_{8} \text { LINK }_{i}+\beta_{9} \text { LIFSPN }_{i}+u_{i}
\end{aligned}
$$

where, $i=$ firm, $u=$ error term and $\beta$ s are the coefficients.

Two different linear regressions, one for 2010-11 and another for 2015-16, have been estimated.

\section{RESULTS AND DISCUSSION}

\section{Number, employment and GVA in unorganised manufacturing enterprises}

Total number of unorganised non-agricultural enterprises in India was accounted for 5 crore 76 lakh and 73 thousand in 2010-11 which significantly increased to 6 crore 33 lakh and 92 thousand in 2015-16. Specifically, the number of own account enterprises (OAEs), enterprises that do not employ any hired worker on a fairly regular basis, increased by 45 lakhs whereas the number of establishment (ESTT), enterprises that employ at least one higher worker throughout the year, increased by 11 lakhs during 2010-11 to 2015-16. The OAEs are 5 times greater than the ESTTs type enterprises in India. UMEs have played an important role in the unorganised sector in India. UMEs had increased from 1 crore 72 lakh and 10 thousand in 2010-11 to 1 crore 96 lakh and 65 thousand in 2015-16. It has increased for both OAEs and ESTT (Table 1).

Total number of workers employed in the nonagricultural enterprises in India was accounted for 10 crore 79 lakh and 78 thousand in 2010-11 which increased to 11 crore 12 lakh and 71 thousand in 2015-16 (Table 2). Employment in OAEs of all the broad activity categories had decreased from 6 crore 97 lakh and 64 thousand in 2010-11 to 6 crore 90 lakh and 85 thousand in 2015-16. In other words, around 7 lakh employment decreased in the OAEs 
during the five years period in India. Therefore, the increase in total employment was due to the increase in the number of employment in the ESTT enterprises. In spite of fall in employment in total OAEs, Table 1 shows an opposite result for the own account manufacturing enterprises (OAMEs). Their employment increased by 18 lakh 25 thousand whereas number of employment in establishment type manufacturing (ESTM) had reduced during 2010-11 to 2015-16. The total unorganised manufacturing enterprises were increased from 3 crore 48 lakh and 88 thousand in $2010-11$ to 3 crore 60 lakh and 41 thousand in 2015-16.

Table 1: Number of Unorganized Enterprises (in thousand) by Activity Category in India, 2010-11 and 2015-16

\begin{tabular}{lllllll}
\hline \multirow{2}{*}{$\begin{array}{l}\text { Broad Activity } \\
\text { Category }\end{array}$} & \multicolumn{2}{c}{ OAE } & \multicolumn{2}{c}{ ESTT } & \multicolumn{2}{c}{ ALL } \\
\cline { 2 - 8 } & $\mathbf{2 0 1 0}$ & $\mathbf{2 0 1 5 -}$ & $\mathbf{2 0 1 0}-$ & $\mathbf{2 0 1 5}-$ & $\mathbf{2 0 1 0}-$ & $\mathbf{2 0 1 5 -}$ \\
\hline Manufacturing & 14430 & 16814 & 2780 & 2851 & 17210 & 19665 \\
Trade & 17824 & 19470 & 2926 & 3565 & 20751 & 23036 \\
Other Services & 16556 & 17072 & 3156 & 3616 & 19712 & 20688 \\
All & 48810 & 53360 & 8862 & 10033 & 57673 & 63392 \\
\hline
\end{tabular}

Source: NSSO Unit Level data of $67^{\text {th }}$ round (2010-11) and $73^{\text {rd }}$ round (2015-16) report.

Table 2: Employment (in thousand) in the Unorganised Sector by Activity in India, 2010-11 and 2015-16

\begin{tabular}{lllllll}
\hline \multirow{2}{*}{ Broad Activity } & \multicolumn{2}{c}{ OAE } & \multicolumn{2}{c}{ ESTT } & \multicolumn{2}{c}{ ALL } \\
\cline { 2 - 7 } Category & $\mathbf{2 0 1 0}$ & $\mathbf{2 0 1 5}$ & $\mathbf{2 0 1 0}$ & $\mathbf{2 0 1 5}-$ & $\mathbf{2 0 1 0}-$ & $\mathbf{2 0 1 5 -}$ \\
& $\mathbf{1 1}$ & $\mathbf{1 6}$ & $\mathbf{1 1}$ & $\mathbf{1 6}$ & $\mathbf{1 1}$ & $\mathbf{1 6}$ \\
\hline Manufacturing & 20844 & 22670 & 14044 & 13372 & 34888 & 36041 \\
Trade & 24506 & 26911 & 9623 & 11827 & 34129 & 38738 \\
Other Services & 24414 & 19500 & 14547 & 16985 & 38961 & 36485 \\
All & 69764 & 69085 & 38214 & 42187 & 107978 & 111271 \\
\hline
\end{tabular}

Source: As in Table 1.

Gross value added (GVA) of unorganised sector for different broad activities and nature of enterprises also increased from 2010-11 to 2015-16. Table 3 shows that total GVA of unorganised sector in India was accounted for ₹ 6,28,356 crore in 2010-11 and it increased to $11,53,206$ crore in 2015-16. That is the total GVA almost doubled during this period. GVA of OAEs in all broad activity categories in 201011 was ₹ 2,82,530 crore which raised to ₹ 5,10,899 crore and for ESTT GVA was 3,45,827 crore and it increased to 6,43,403 crore in 2015-16. If we consider total UMEs, the value of GVA raised from ₹ 56,612 crore in $2010-11$ to $₹ 1,04,481$ crore in $2015-16$ for OAMEs category and in case of ESTM enterprises the value of GVA was less than double, it changed from ₹ 3,45,827 crore in 2010-11 to ₹ 6,43,403 crore in 2015-16. Total GVA of UMEs increased from $₹ 1,54,720$ crore in $2010-11$ to $₹ 2,68,066$ crore in 2015-16.

Table 3: GVA (in ₹ Crore) in the Unorganised Sector by Activity in India , 2010-11 and 2015-16

\begin{tabular}{|c|c|c|c|c|c|c|}
\hline \multirow{2}{*}{$\begin{array}{l}\text { Broad } \\
\text { Activity } \\
\text { Category }\end{array}$} & \multicolumn{2}{|c|}{ OAE } & \multicolumn{2}{|c|}{ ESTT } & \multicolumn{2}{|c|}{ ALL } \\
\hline & $\begin{array}{l}2010- \\
11 \\
\end{array}$ & 2015-16 & $\begin{array}{l}2010- \\
11 \\
\end{array}$ & $\begin{array}{l}2015- \\
16\end{array}$ & $\begin{array}{l}2010- \\
11\end{array}$ & 2015-16 \\
\hline $\begin{array}{l}\text { Manufac- } \\
\text { turing }\end{array}$ & 56612 & & 98108 & & & \\
\hline Trade & 129821 & & 113904 & & 243725 & \\
\hline $\begin{array}{l}\text { Oth } \\
\text { Serv }\end{array}$ & 96097 & 170648 & 133814 & 266665 & 229911 & 436224 \\
\hline All & 282530 & 510899 & 345827 & 643403 & 628356 & 1153206 \\
\hline
\end{tabular}

Source: As in Table 1.

\section{Productivity of UMEs in India}

Labour productivity has increased for OAMEs, ESTMs and ALLMs during 2010-11 to 2015-16. Productivity of capital remained same for different types of enterprises during this 2010-11 to 201516. The use of capital per labour in OAMEs also increased from 2010-11 to 2015-16. But in the other two types of enterprises the use of capital reduced during the period (Table 4).

Table 4: Partial Productivity of Labour, Capital and Capital Intensity, 2010-11 and 2015-16

\begin{tabular}{lllll}
\hline $\begin{array}{l}\text { Enterprise } \\
\text { Type }\end{array}$ & Year & $\begin{array}{l}\text { Labour } \\
\text { Productivity }\end{array}$ & $\begin{array}{l}\text { Capital } \\
\text { Productivity }\end{array}$ & $\begin{array}{l}\text { Capital } \\
\text { Intensity }\end{array}$ \\
\hline \multirow{2}{*}{ OAME } & $2010-11$ & 92.21 & 0.37 & 246.33 \\
& $2015-16$ & 132.22 & 0.57 & 628.38 \\
ESTM & $2010-11$ & 270.22 & 0.37 & 726.38 \\
& $2015-16$ & 360.36 & 0.57 & 628.38 \\
ALLM & $2010-11$ & 156.95 & 0.37 & 420.92 \\
& $2015-16$ & 215.57 & 0.57 & 377.05 \\
\hline
\end{tabular}

Source: Authors' Calculation, NSSO $67^{\text {th }}$ round (2010-11) and 73 ${ }^{\text {rd }}$ round (2015-16) Unit Level data.

Table 5 shows the estimated Cobb-Douglas production function for OAMEs, ESTM and ALLMs for the year 2010-11. It is estimated by OLS method on the basis of unit level data of UMEs. The 
Table 5: OLS Estimates of CDPF for UMEs, 2010-11

\begin{tabular}{|c|c|c|c|c|c|c|c|c|}
\hline & & Coefficient & Std. Error & t-value & p-value & Adjusted R Square & $\alpha+\beta$ & $\begin{array}{l}\text { Marginal } \\
\text { Productivity }\end{array}$ \\
\hline \multirow[t]{3}{*}{ OAMES } & Constant & 3.31 & 0.030 & 109.39 & 0.000 & & & - \\
\hline & Labour & 0.62 & 0.003 & 191.89 & 0.000 & 0.77 & 0.942 & 57.54 \\
\hline & Capital & 0.32 & 0.003 & 112.19 & 0.000 & & & 0.119 \\
\hline \multirow[t]{3}{*}{ ESTMS } & Constant & 1.58 & 0.013 & 121.37 & 0.000 & & & - \\
\hline & Labour & 0.78 & 0.004 & 218.34 & 0.000 & 0.87 & 1.011 & 210.77 \\
\hline & Capital & 0.23 & 0.004 & 80.38 & 0.000 & & & 0.080 \\
\hline \multirow[t]{3}{*}{ ALLMS } & Constant & 0.65 & 0.008 & 78.16 & 0.000 & & & -- \\
\hline & Labour & 0.67 & 0.003 & 242.77 & 0.000 & 0.96 & 1.128 & 105.47 \\
\hline & Capital & 0.45 & 0.002 & 225.54 & 0.000 & & & 0.170 \\
\hline
\end{tabular}

Source: As in Table 4.

Table 6: OLS Estimates of CDPF for UMEs, 2015-16

\begin{tabular}{|c|c|c|c|c|c|c|c|c|}
\hline & & Coefficient & Std. Error & t-value & p-value & Adjusted R Square & $\alpha+\beta$ & $\begin{array}{l}\text { Marginal } \\
\text { Productivity }\end{array}$ \\
\hline \multirow[t]{3}{*}{ OAMES } & Constant & 4.28 & 0.033 & 128.7 & 0.00 & & & - \\
\hline & Labour & 0.64 & 0.004 & 181.0 & 0.00 & 0.75 & 0.918 & 84.49 \\
\hline & Capital & 0.28 & 0.003 & 90.6 & 0.00 & & & 0.16 \\
\hline \multirow[t]{3}{*}{ ESTMS } & Constant & 7.39 & 0.026 & 167.0 & 0.00 & & & - \\
\hline & Labour & 0.82 & 0.003 & 255.9 & 0.00 & 0.88 & 1.013 & 294.52 \\
\hline & Capital & 0.20 & 0.003 & 75.4 & 0.00 & & & 0.11 \\
\hline \multirow[t]{3}{*}{ ALLMS } & Constant & 4.07 & 0.024 & 169.3 & 0.00 & & & - \\
\hline & Labour & 0.66 & 0.003 & 247.7 & 0.00 & 0.78 & 0.957 & 142.62 \\
\hline & Capital & 0.29 & 0.002 & 129.8 & 0.00 & & & 0.17 \\
\hline
\end{tabular}

Source: As in Table 4.

marginal productivity of labour is much higher than the marginal productivity of capital for all the types of enterprises. The marginal productivity of labour in ESTMs is higher than the marginal productivity of labour in OAMEs. Labour and capital are also statistically significantly related with GVA for all the types of enterprises. All the explanatory variables are positively related with GVA. In case of ALLMs, if labour is increased by 1 per cent then the GVA is increased by 0.67 per cent whereas if capital is increased by 1 per cent then the GVA increased by 0.45 per cent. The explanatory variables explain 77 per cent variation of GVA of OAMEs, 87.5 per cent in case of ESTMs and 96.4 per cent for ALLMs. Except the OAMEs, other two categories have shown increasing returns to scale (IRS).

Table 6 shows the estimated Cobb-Douglas production function for OAMEs, ESTM and ALLMs for the year 2015-16. The marginal productivity of labour is much higher than the marginal productivity of capital for all the types of enterprises.
The marginal productivity of labour in ESTMs is higher than the marginal productivity of labour of OAMEs. The dependent variables are significantly related with GVA for each type of enterprise. GVA is positively related with the explanatory variables for all types of enterprises. GVA of UMEs is much more affected by the change in labour than capital for all the types of enterprises. The explanatory variables explain 75 per cent variation of GVA of OAMEs and 87.8 per cent for ESTMs and 77.5 per cent for ALLMs. ESTMs run under IRS whereas the OAMEs run under decreasing returns to scale (DRS).

The relationship between labour productivity and characteristics of UMEs is explained by the estimated results of regression equation as given in Table 7 for the year 2010-11 and Table 8 for the year 2015-16. The labour productivity (for the year 2010-11) is positively and significantly influenced by male ownership (OWRSP; Male $=1$, otherwise $=0)$, own account enterprises (ENT; ESTM $=1$, otherwise $=0$ ), enterprises do not face problem 
Table 7: Estimation of the Regression Equation, 2010-11

\begin{tabular}{|c|c|c|c|c|}
\hline \multicolumn{5}{|c|}{ Number of observations $=75456$} \\
\hline \multicolumn{5}{|c|}{$\mathrm{F}=1055.2$} \\
\hline \multicolumn{5}{|l|}{ Prob. $=0.000$} \\
\hline \multicolumn{5}{|l|}{$\mathrm{R}$ square $=0.138$} \\
\hline \multicolumn{5}{|c|}{ Adjusted R square $=0.138$} \\
\hline $\begin{array}{l}\text { Dependent Variable: } \\
\text { PRODUCTIVITY }\end{array}$ & Coefficient & Std. Err. & $t$ value & $\mathrm{p}$ value \\
\hline (Constant) & 81.78 & 1.77 & 46.26 & 0.000 \\
\hline LOCN & -33.25 & 1.20 & -27.68 & 0.000 \\
\hline OWRSP & 56.17 & 1.47 & 38.08 & 0.000 \\
\hline ENT & 38.06 & 1.36 & 27.95 & 0.000 \\
\hline PROB & 15.14 & 1.24 & 12.23 & 0.000 \\
\hline GOVAT & 21.21 & 4.09 & 5.18 & 0.000 \\
\hline STGR & 19.53 & 1.26 & 15.55 & 0.000 \\
\hline REG & 56.13 & 1.41 & 39.92 & 0.000 \\
\hline LINK & -34.58 & 2.02 & -17.11 & 0.000 \\
\hline LIFSPN & -0.09 & 0.03 & -2.78 & 0.005 \\
\hline
\end{tabular}

Source: As in Table 4.

Table 8: Estimation of the Regression Equation, 2015-16

\begin{tabular}{lllll}
\hline Number of observations $=79689$ & & & & \\
$\mathrm{~F}=970.041$ & & & & \\
Prob. $=0.000$ & & & & \\
R square = 0.099 & & & & \\
Adjusted R square = 0.099 & Coefficient & Std. Err. & t value & P value \\
\hline Dependent Variable: & & & 43.11 & 0.000 \\
PRODUCTIVITY & 140.99 & 3.27 & -28.00 & 0.000 \\
\hline (Constant) & -61.04 & 2.18 & 34.72 & 0.000 \\
LOCN & 91.69 & 2.64 & 25.64 & 0.000 \\
OWRSP & 63.50 & 2.48 & 9.44 & 0.000 \\
ENT & 20.84 & 2.21 & 2.28 & 0.022 \\
PROB & 20.59 & 9.02 & 13.87 & 0.000 \\
GOVAT & 32.75 & 2.36 & 39.42 & 0.000 \\
STGR & 100.64 & 2.56 & -7.07 & 0.000 \\
REG & -22.67 & 3.20 & -3.04 & 0.002 \\
LINK & -0.37 & 0.12 & & \\
LIFSPN & & & & \\
\hline
\end{tabular}

Source: As in Table 4.

(PROB; Yes =0, No=1), expanding status of growth (STGR; Expanding = 1, otherwise $=0$ ), government assistant (GOVAT; Received $=1$, Otherwise $=0$ ) and registration of enterprises (REG; if registered $=1$, otherwise $=0)$. But the location $(\mathrm{LOCN}$; Urban = 1 , otherwise $=0$ ), having linkage of the enterprise with other units (LINK; Yes $=1$, otherwise $=0$ ) and lifespan are negatively related with labour productivity (Table 7).
The relationship is quite similar in the year 201516. The labour productivity is positively and significantly influenced by male ownership (OWRSP; Male $=1$, otherwise $=0$ ), own account enterprises $($ ENT; ESTM $=1$, otherwise $=0)$, enterprises do not face problem (PROB; Yes $=0$, No = 1), expanding status of growth (STGR; Expanding = 1, otherwise $=0$ ), government assistant (GOVAT; Received $=1$, Otherwise $=0$ ) and registration of enterprises (REG; 
if registered $=1$, otherwise $=0$ ). But the location $($ LOCN; Urban $=1$, otherwise $=0)$, having linkage of the enterprise with other units (LINK; Yes = 1, otherwise $=0$ ) and lifespan are negatively related with labour productivity (Table 8).

\section{CONCLUSION}

Number of unorganised manufacturing enterprises (UMEs) had increased significantly in India during 2010-11 to 2015-16. Total number of workers employed in the UMEs had also increased by 3,293 thousand during 2010-11 to 2015-16. GVA in India which accounted for Rs. 6,28,356 crore in 2010-11 also increased to $11,53,206$ crore in 2015-16. That is the total GVA almost doubled during this period. These phenomena show the glory picture of UMEs in India. The average productivity of labour has increased for OAMEs, ESTMs and ALLMs during 2010-11 to 2015-16. The marginal productivity of labour is much higher than the marginal productivity of capital. ESTMs showed increasing returns to scale. The labour productivity is positively and significantly influenced by male ownership, own account enterprises, enterprises do not face problem, expanding status of growth, government assistance and registration of enterprises. Whereas the location, having linkage of the enterprise with other units and lifespan are negatively related with labour productivity.

\section{REFERENCES}

Agyapong, D. 2010. Micro, Small and Medium Enterprises' Activities, Income Level and Poverty Reduction in Ghana - A Synthesis of Related Literature. Int. J. Business and Mgt., 5(12): 196-205.

Anupama. 2007. Gender Discrimination in Quality Of Employment And Wages In Unorganised Manufacturing Sector of India. The Indian . Labour Eco., 50(4): 1007-1019.

Behera, B. 2011. Role of Microenterprise in Livelihood Promotion: A Perspective Study in India. Annual Summit on Business and Entrepreneurial Studies (ASBES 2011) Proceeding, Odisha, India, pp. 68-81

Bhavani, T.A. and Bhanumurthy, N.R. 2015. Financial Access - Measurement and Determinants: A Case Study of Unorganised Manufacturing Enterprises in India. National Institute of Public Finance and Policy, Working Paper No. 2015-143.

Census of India. 2001. Population Projections for India and States 2001-2026. Report of the Technical Group on Population Projections Constituted by the National Commission on Population. May 2006.
Das, P. and Das, B. 2017. Characteristics and Status of Growth of Micro Manufacturing Enterprises in West Bengal: An Analysis based on NSSO Unit Level Data. Sarvekshana, 32(3 \& 4): 1-24.

Das, P. and Das, B. 2017. Status of Micro Manufacturing in West Bengal: An Analysis based on NSSO Unit Level Data. Vidyasagar University J. Eco., XVIII: 45-50.

Devi, M. 2019. Study of Climatic Factors Affecting the Productivity of Cotton and its Instability. Eco. Affa., 64(4): 761-767.

Ganguly, S. 2013. Micro, Small and Medium Enterprises In West Bengal: An Evaluation. Int. J. Res. Com. E Mgt., 4(10).

Goldar, B. and Mitra, A. 2013. Small versus large manufacturing units: how efficient are they?. J. Asia Pacific Eco., pp. 634653.

Gurung, S. 2007. Social Inclusion Dalits through Microenterprise: A Case Study MEDEP in Nawalparasi District. Micro-Enterprises, Development for Poverty Alleviation, Chapter-V, Micro-Enterprise Development Programme (MEDEP), Nepal, pp. 164-172.

Islam, R. 1987. Rural Industrialization and Employment in Asia. ILO (ARTEP), New Delhi.

Kanitkar, A. 1994. Entrepreneurs and Micro-Enterprises in Rural India. Eco. Pol. Weekly, 29(9): 25-30.

Kumar, P.S. and Reddy, B.B. 2014. Micro Manufacturing Enterprises: Use of Local Resources. Ind. J. Appl. Res., 4(8)

Maiti, K. et al. 2018. Male out migration and its impact on women empowerment in West Bengal. Eco. Affa., 63(2): 207-215.

Maity, K. et al. 2019. Child Immunization: A comparative Study across States in India. Economic Affairs, 64(1): 207215.

Manikandan, N., Kanagasabapathi, P. and Sreeleakha, P. 2016. Growth of Unorganized Manufacturing Sector in India Analysis of National Sample Survey Studies. IOSR J. Busi. Mgt., 18(11): 01-07.

Palit, S. 2018. Unorganised Manufacturing Sector In India: Challenges and Opportunities. Int. J. Mgt., 9(4): 10-13.

Sankarappa, P., Redddy, S.S. and Reddy, B.B. 2016. Marketing Practice of Micro Manufacturing Enterprises" J. Innova. Res. Sols. (JIRAS), 2: 59-68.

Sathish, A. and Tarpe, A. 2014. Issues and Problems in the Growth of Micro, Small and Medium Enterprises in Goa: An Empirical Study. Int. J. Sci. Res., 3(7): 102-106.

Sen, K. and Salim, S. 2016. Micro, Small and Medium Enterprises in West Bengal-An Inter-District Analysis. Int. J. Sci. Res., 5(2): 225-230.

Sharma, A., Dua, S. and Hatwal, V. 2012. Micro Enterprise Development And Rural Women Entrepreneurship: Way For Economic Empowerment. J. Eco. Mgt., 1(6) :114-127.

Siddeswari, G.K. et al. 2020. Types and Sales of Enterprises Being Run by the Women Entrepreneur of Self-Help Groups in Andhra Pradesh. Eco. Affa., 65(1): 57-62.

Subedi and Bimala. 2006. Products Marketing by Entrepreneurs: A Case Study of MEDEP in Dhanusha 


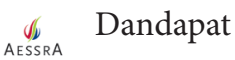

District. Micro-Enterprises, Development for Poverty Alleviation, Chapter-VI, Micro-Enterprise Development Programme (MEDEP), Nepal, pp. 183-192.

Subramaniam, T. 2010. Micro Enterprise And Employment Creation Among The Youth In Malaysia". Jati, Volume 15, December 2010, pp. 151-166.
Subramanian, K. 2014. Impact of New Economic Reforms on Industry. Eco. Affa., 59(2): 129-135.

Tripathi, R. and Ahmad, I. 2015. Prospect for unorganised manufacturing sector in India: A comparative study with respect to China. Int. J. Appl. Res., pp. 170-172. 